\title{
Influence of Zn on Structure and Magnetic Properties of Rapid Quenched (Fe-Zn)-Cu-Nb-Si-B Alloys
}

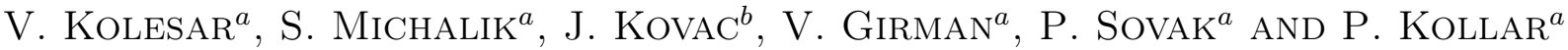 \\ ${ }^{a}$ Institute of Physics, P.J. Safarik University, Park Angelinum 9, 04154 Kosice, Slovakia \\ ${ }^{b}$ Institute of Experimental Physics, Slovak Academy of Science, Watsonova 47, 04101 Kosice, Slovakia \\ The aim of this work was to study the influence of $\mathrm{Zn}$ on the formation of nanostructure in \\ $\mathrm{Fe}_{73.5-x} \mathrm{Zn}_{x} \mathrm{Cu}_{1} \mathrm{Nb}_{3} \mathrm{Si}_{13.5} \mathrm{~B}_{9}(x=1,3,5)$ ribbons prepared by the melt-spinning technique. X-ray diffrac- \\ tion measurements proved amorphous state of the sample with $x=1$. The sample with $x=3$ contains a small \\ fraction of $\mathrm{Fe}_{3} \mathrm{Si}$ phase and the sample with $x=5$ is in nanocrystalline state with the average grain size of about \\ $25 \mathrm{~nm}$. The reduced radial distribution function $G(r)$ was calculated for local structure investigation. Increasing \\ Zn content enhances crystallization during solidification which leads to increase of magnetocrystalline anisotropy \\ and consequently to increase of coercivity.
}

PACS numbers: 61.46.Hk, 75.50.Bb, 75.75.Cd

\section{Introduction}

Nanocrystalline $\mathrm{Fe}-\mathrm{Cu}-\mathrm{Nb}-\mathrm{Si}-\mathrm{B}$ alloy prepared from amorphous state by annealing at about $550^{\circ} \mathrm{C}$ has excellent magnetic properties and a lot of potential applications such as magnetic parts of power transfers, magnetic sensors, actuators etc. [1-3]. Manufacturing of this alloy consists of two steps, i.e., formation of amorphous precursor by rapid solidification followed by well defined annealing which leads to formation of nanocrystalline phase $[4,5]$. Annealing is energetically difficult process and production of nanocrystalline ribbons directly by the melt-spinning technique would be much advantageous. It was shown that the addition of $\mathrm{Zn}$ to the $\mathrm{Fe}_{73.5} \mathrm{Si}_{13.5} \mathrm{~B}_{9} \mathrm{Nb}_{3} \mathrm{Cu}_{1-x} \mathrm{Zn}_{x}(x=0.5,1)[6]$ and $\mathrm{Zr}_{65} \mathrm{Al}_{7.5} \mathrm{Ni}_{5} \mathrm{Cu}_{17.5} \mathrm{Zn}_{5}[7]$ resulted in crystallization enhancement. In this paper we explore magnetic properties and crystallization as a consequence of rapid solidification process in $\mathrm{Fe}_{73.5-x} \mathrm{Zn}_{x} \mathrm{Cu}_{1} \mathrm{Nb}_{3} \mathrm{Si}_{13.5} \mathrm{~B}_{9}(x=1,3,5)$ ribbons employing melt-spinning technique.

\section{Experimental}

The samples in form of ribbons with chemical composition $\mathrm{Fe}_{73.5-x} \mathrm{Zn}_{x} \mathrm{Cu}_{1} \mathrm{Nb}_{3} \mathrm{Si}_{13.5} \mathrm{~B}_{9}(x=1,3,5)$ were prepared by melt spinning technique. The ribbons are $2 \mathrm{~mm}$ wide and $50 \mu \mathrm{m}$ thick at the linear speed of cooling rate $30 \mathrm{~m} / \mathrm{s}$. Their structure was investigated by X-ray diffraction (XRD) method. XRD measurements were performed at the BW5 beamline at DESY/HASYLAB (Hamburg, Germany). The samples were illuminated for $20 \mathrm{~s}$ by X-rays of wavelength $0.124 \AA$. XRD patterns were collected in symmetric transmission geometry using a MAR 345 two-dimensional (2D) image plate detector $\left(2300 \times 2300\right.$ pixels, $150 \times 150 \mu \mathrm{m}^{2}$ pixel size), which was mounted perpendicular to the incident X-ray beam. Radiation energy was determined by fitting a standard reference $\mathrm{LaB}_{6}$ sample. The saturation magnetization $\left(M_{\mathrm{S}}\right)$ measurements of as-quenched ribbons were performed by vibration sample magnetometer (VSM). Coercivity was determined from hysteresis loops traced with fluxmeter in quasi DC magnetic field.

\section{Results and discussion}

The XRD patterns of $\mathrm{Fe}_{73.5-x} \mathrm{Zn}_{x} \mathrm{Cu}_{1} \mathrm{Nb}_{3} \mathrm{Si}_{13.5} \mathrm{~B}_{9}$ $(x=1,3,5)$ as-quenched ribbons are presented in Fig. 1. The Bragg peaks in XRD pattern of $x=5$ belong to cubic $\mathrm{Fe}_{3} \mathrm{Si}$ phase (ICSD 412838, space group: $\mathrm{Fm} 3 \mathrm{~m}$ ). The average grain size of $\mathrm{Fe}_{3} \mathrm{Si}$ phase $(\approx 25 \mathrm{~nm})$ was determined from the Debye-Scherrer equation [8]:

$$
L=\frac{(0.9) \lambda}{\beta \cos \theta} .
$$

Here, $L$ is the coherent length, $\lambda$ is the X-ray wavelength, $\beta$ is the full-width at half-maximum of the XRD peak and $\theta$ is the Bragg angle. Small crystalline fraction $\mathrm{Fe}_{3} \mathrm{Si}$ phase is detectable in $x=3$ sample (small Bragg peaks) as well. Only the sample $x=1$ is in a fully amorphous state as it is documented by its diffraction profile consisting of two diffuse peaks without any indications of the Bragg peaks.

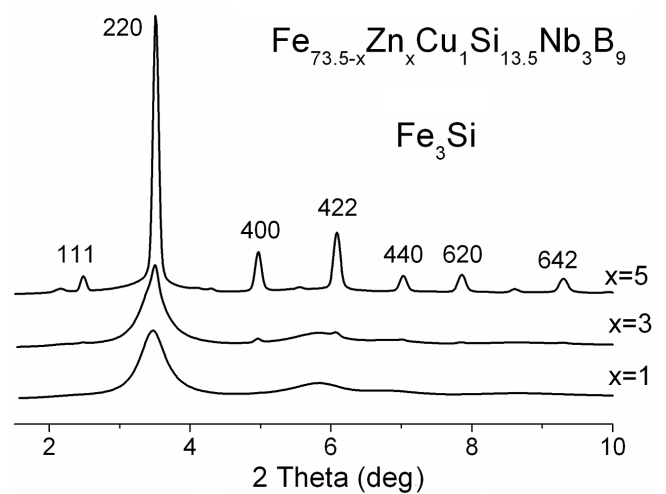

Fig. 1. XRD patterns of $\mathrm{Fe}_{73.5-x} \mathrm{Zn}_{x} \mathrm{Cu}_{1} \mathrm{Nb}_{3} \mathrm{Si}_{13.5} \mathrm{~B}_{9}$ $(x=1,3,5)$ as quenched ribbons. Indexed peaks correspond to the Bragg reflections of $\mathrm{Fe}_{3} \mathrm{Si}$ phase.

The Fourier inversion of structural factor $S(Q)$ obtained from diffraction data gives the reduced radial dis- 
tribution function

$$
G(r)=\frac{2}{\pi} \int_{Q_{\min }}^{Q_{\max }} Q[S(Q)-1] \sin (Q r) \mathrm{d} Q,
$$

where $Q$ is the momentum transfer. The $G(r)$ provides information about probability of finding an atom in spherical shell at a distance $r$ from an arbitrary atom.

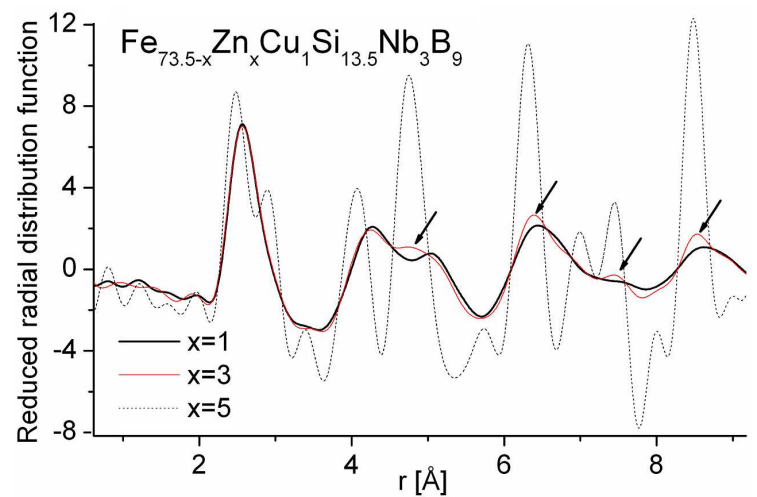

Fig. 2. Reduced radial distribution function of $\mathrm{Fe}_{73.5-x} \mathrm{Zn}_{x} \mathrm{Cu}_{1} \mathrm{Nb}_{3} \mathrm{Si}_{13.5} \mathrm{~B}_{9}(x=1,3,5)$ as-quenched ribbons. Differences between $G(r)$ functions for $x=1$ and $x=3$ samples are marked with inclined arrows.

TABLE

Summarization of magnetic parameters for the as-quenched and annealed $\mathrm{Fe}_{73.5-x} \mathrm{Cu}_{1} \mathrm{Si}_{13.5} \mathrm{~B}_{9} \mathrm{Nb}_{3} \mathrm{Zn}_{x}$ $(x=1,3,5)$ ribbons.

\begin{tabular}{l|c|c}
\hline \hline & $M_{\mathrm{s}}\left[\mathrm{A} \mathrm{m}^{2} \mathrm{~kg}^{-1}\right]$ & $H_{\mathrm{c}}\left[\mathrm{A} \mathrm{m}^{-1}\right]$ (as-quenched) \\
\hline$x=1$ & 127.4 & 4.77 \\
$x=3$ & 112.8 & 6.8 \\
$x=5$ & 81.1 & 12.5
\end{tabular}

The determined $G(r)$ functions of $\mathrm{Fe}_{73.5-x} \mathrm{Zn}_{x} \mathrm{Cu}_{1} \mathrm{Nb}_{3} \mathrm{Si}_{13.5} \mathrm{~B}_{9}(x=1,3,5)$ as-quenched samples are shown in Fig. 2.

With increasing degree of structural ordering amplitudes and sharpness of $G(r)$ function increase as it can be seen in Fig. 2. $G(r)_{x=5}$ shows pronounced and well defined maxima, whose positions are in good agreement with the interatomic distances in the $\mathrm{Fe}_{3} \mathrm{Si}$ structure. On the other hand, maxima of $G(r)_{x=1}$ and $G(r)_{x=3}$ are evidently broader than those of $G(r)_{x=5}$. Additionally it is seen that main peaks (in the interval 2-3.5 $\AA$ ) of $G(r)_{x=1}$ and $G(r)_{x=3}$ are very similar suggesting a similar short local ordering in both, $x=1$ and $x=3$ samples. Deviations from this similarity (marked with inclined arrows in Fig. 2) are clearly visible for distances $r$ greater than $4.5 \AA$. These differences reflect the fact that the $x=3$ sample contains small amount of crystalline $\mathrm{Fe}_{3} \mathrm{Si}$ phase in the amorphous matrix compared with the fully amorphous $x=1$ sample (Fig. 2 ).
The values of coercivity of as-quenched samples (Table) are apparently lower in comparison to the results of $[6]$ ( $\approx 26 \mathrm{~A} / \mathrm{m}$ for as-quenched samples). Increasing value of coercivity with higher $\mathrm{Zn}$ content can be interpreted as follows: Crystallization of investigated samples (see Fig. 1, Fig. 2) is a result of rapid solidification process which leads to hinder domain wall movement (magnetocrystalline anisotropy increasing) [9], analogous to the results reported in [6]. The decrease of magnetocrystalline anisotropy (magnetic softening) can be reached by annealing process when the nanostructure is created after (or as a consequence) of structural relaxation process $[10]$.

The decrease of $M_{\mathrm{S}}$ values (listed in Table) is caused by decreasing Fe content.

\section{Conclusion}

From prepared $\mathrm{Fe}_{73.5-x} \mathrm{Zn}_{x} \mathrm{Cu}_{1} \mathrm{Nb}_{3} \mathrm{Si}_{13.5} \mathrm{~B}_{9}(x=1$, 3,5 ) as-quenched ribbons the $x=1$ sample was in amorphous state. The $x=3$ sample contains a small fraction of $\mathrm{Fe}_{3} \mathrm{Si}$ phase and the sample with $x=5$ is in nanocrystalline state with the average grain size of about $25 \mathrm{~nm}$. The shape of main peaks (in the range $2-3.5 \AA$ ) of $G(r)_{x=1}$ and $G(r)_{x=3}$ indicate similar short local ordering in both, $x=1$ and $x=3$ samples. Increasing Zn content enhances crystallization during solidification which leads to increase of magnetocrystalline anisotropy and consequently to increasing value of coercivity.

\section{Acknowledgments}

The paper was supported by Slovak Grant Agency VEGA (1/0167/10 and 1/0311/10) and it was done in the frame of the project "Centre of Excellence of progressive materials with nano- and submicron microstructure", with support of the Operational Program Research and Development financed from European Regional Development Fund.

\section{References}

[1] Y. Yoshizava, S. Oguma, K. Yamauchi, J. Appl. Phys. 64, 6044 (1988).

[2] K. Suzuki, A. Makino, A. Inoue, T. Masumoto, J. Appl. Phys. 70, 6232 (1991).

[3] W. Lu, L. Yang, B. Yan, W.H. Huang, Mater. Sci. Eng. 128, 179 (2006).

[4] M.A. Willard, D.E. Laughlin, M.E. McHenry, D. Thoma, K. Sickafus, J.O. Cross, V.G. Harris, J. Appl. Phys. 84, 6773 (1998).

[5] G. Herzer, in: Handbook of Magnetic Materials, Ed. K.H.J. Buschow, Vol. 10, Amsterdam 1997, p. 415.

[6] N. Chau, N.Q. Hoa, N.D. The, L.V. Vu, J. Magn. Magn. Mater. 303, 415 (2006).

[7] Ch. Li, A. Inoue, J. Alloys Comp. 325, 230 (2001).

[8] R. Nowosielski, J.J. Wysocki, I. Wnuk, P. Gramatyka, J. Mater. Process. Technol. 175, 324 (2006).

[9] V. Franco, C.F. Conde, A. Conde, J. Magn. Magn. Mater. 185, 353 (1998).

[10] J.M. Borrego, C.F. Conde, A. Conde, Matter. Sci. Eng. 304, 491 (2001). 